\title{
TAR (THROMBOCYTOPENIA WITH ABSENT RADIUS) SYNDROME WITH CONGENITAL ACYANOTIC HEART DISEASE: A RARE CASE REPORT
}

\author{
Ashok S. Jagtap ${ }^{1}$, Ankit Gupta², C. D. Aundhakar³, Lekha Mishra4, Umardand Mahesh ${ }^{5}$ \\ ${ }^{1}$ Associate Professor, Department of Paediatrics, Krishna Institute of Medical Sciences, Karad. \\ ${ }^{2}$ Resident, Department of Paediatrics, Krishna Institute of Medical Sciences, Karad. \\ ${ }^{3}$ Professor, Department of Paediatrics, Krishna Institute of Medical Sciences, Karad. \\ ${ }^{4}$ Resident, Department of Paediatrics, Krishna Institute of Medical Sciences, Karad. \\ ${ }^{5}$ Consultant, Department of Paediatrics, Krishna Institute of Medical Sciences, Karad.
}

\begin{abstract}
It is a rare genetic disorder characterized by the absence of the radius bone in the forearm and a dramatically reduced platelet count. This syndrome may occur as a part of the 1q21.1 deletion syndrome. Symptoms of thrombocytopenia or a lowered platelet count leads to bruising and potentially life-threatening haemorrhage. Affected children who survive this period and do not have damaging haemorrhages in the brain usually have a normal life expectancy and normal intellectual development. Other common links between with TAR seem to include heart problems, kidney problems, knee joint problems, frequently lactose intolerance and often thumb hypoplasia. The incidence is $0.5-1$ per 100,000 live births. Mutations in the RBM8A gene cause TAR syndrome. It is inherited in an autosomal recessive pattern. This disorder is to be differentiated from Holt-Oram syndrome, which has similar presentation. Prevention of bleeding with physiotherapy and occupational therapy are mainstay of management. With this case report we try to discuss the complexity of the condition and its management in the neonatal period.
\end{abstract}

\section{KEYWORDS}

Haemorrhage, Genetic, TAR, Thrombocytopenia.

HOW TO CITE THIS ARTICLE: Jagtap AS, Gupta A, Aundhakar CD, et al. TAR (thrombocytopenia with absent radius) syndrome with congenital acyanotic heart disease: a rare case report. J. Evolution Med. Dent. Sci. 2016;5(22):1208-1209,

DOI: $10.14260 /$ jemds/2016/281

\section{INTRODUCTION}

Thrombocytopenia and Absent Radius syndrome (TAR) is a rare genetic disorder, which is inherited as an autosomal recessive trait. This disorder is characterized by low levels of platelets in blood (Thrombocytopenia) resulting in potentially severe bleeding episodes primarily during infancy. Other characteristic findings include bilateral radial aplasia. Other characteristics include other limb abnormalities as well as intermittent leucocytosis, eosinophilia, anaemia secondary to haemorrhage, cardiac defects, renal anomalies, mental retardation and milk protein allergy. The prevalence of TAR syndrome is estimated at 1:200,000-1:100,000. TAR syndrome is the result of noncoding single nucleotide polymorphisms located in the 5'UTR region or the first intron of the gene RBM8A and also because of microdeletion of chromosome 1q21.1 region with an additional as yet unknown modifier. ${ }^{1}$

\section{CASE HISTORY}

A full-term male neonate of full-term pregnancy born via normal vaginal delivery presented with abnormality of both upper limbs. Baby was first child of non-consanguineous parents and cried immediately after birth with Apgar score of 7 and 9 at 1 and 5 minutes respectively. There was no $\mathrm{H} / \mathrm{O}$ any birth trauma or similar illness in the family. Pregnancy was uneventful without any $\mathrm{H} / \mathrm{O}$ maternal illness or drug intake.

Financial or Other, Competing Interest: None.

Submission 30-01-2016, Peer Review 27-02-2016,

Acceptance 04-03-2016, Published 17-03-2016.

Corresponding Author:

Dr. Ankit Gupta,

Ward No. 14,

Department of Paediatrics,

Krishna Institute of Medical Sciences,

Karad, Maharashtra.

E-mail: drankitguptamd@gmail.com

DOI: $10.14260 /$ jemds/2016/281
On physical examination vital signs were stable and baby was alert, pink and active. Baby had a healthy birth weight of $3.120 \mathrm{~kg}$. Length was $51 \mathrm{~cm}$ and head circumference $34 \mathrm{~cm}$. There were no facial dysmorphic features. Bilateral deformity with radial deviation of both the upper limbs was noted. No deformity in the lower limbs was present. No organomegaly was present and other systems were grossly normal. Laboratory parameters were as Hb-18.1, Total counts-45600, N-67\%, L-27\%, E-6\%, Platelet-30,000, PCV-59.9\%. Other parameters were grossly normal.

X-ray showed bilateral absent radius, which was confirmed with orthopaedic consultation. USG abdomen and pelvis and neuro-USG showed no obvious abnormality. 2D Echo was done, which showed anterior muscular VSD $(2.2 \mathrm{~mm})$ and tiny PFO with left to right flow. Based on these physical findings, thrombocytopenia and X-ray results diagnosis of TAR syndrome was made. Genetic testing could not be done as relatives were not willing and baby was discharged on request.

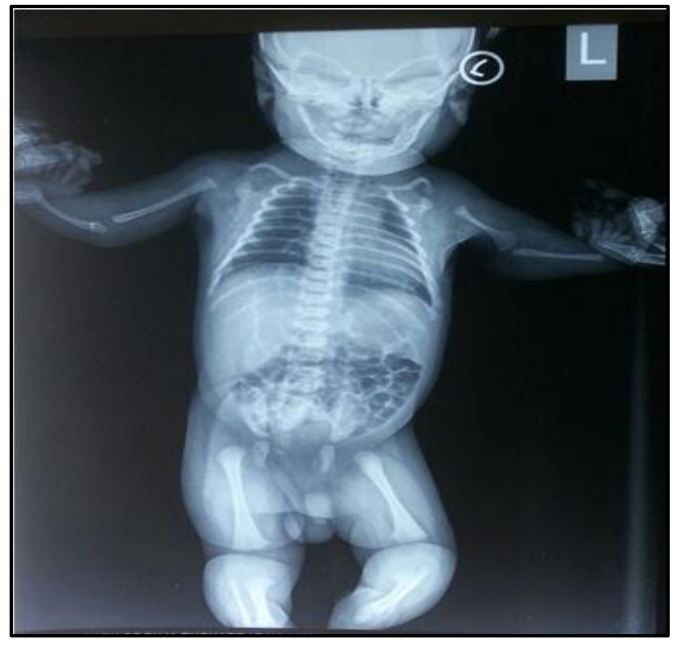

Fig. 1a 


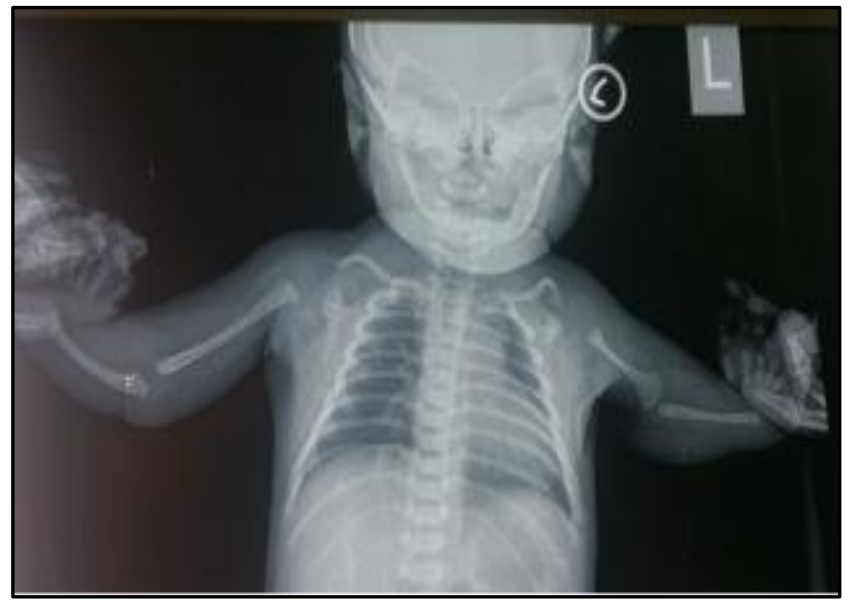

Fig. $1 b$

Fig. 1a \& 1b: Plain radiograph of both the upper limbs showed congenital absence of radius

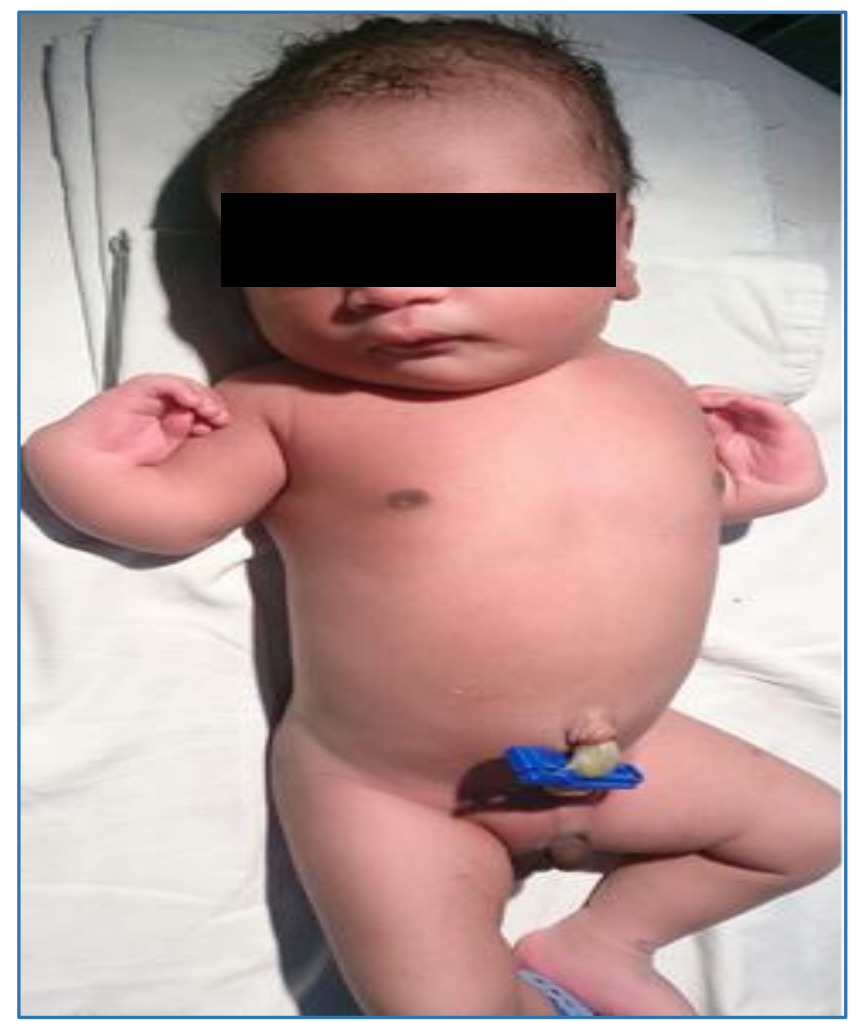

Fig. 2: Radial deviation of the right upper limb with no thumb deformity

\section{DISCUSSION}

TAR syndrome is a rare genetic disorder characterized by low platelet level and radial aplasia and presence of both thumbs. ${ }^{2}$ Thrombocytopenia, which may be transient, is seen in $100 \%$ of cases diagnosed with TAR syndrome. ${ }^{3}$ The upper limb abnormalities range from isolated absent radii with normal thumbs as seen in our case. Lower extremity anomalies occur in $46 \%$ of patients, but are usually less severe than those of the upper limbs. These abnormalities include hip dislocation, femoral torsion, tibia torsion and deformity of the knee. ${ }^{4}$ None of these were seen in our case. The fingers and thumbs are always present. Cardiac anomalies, particularly the Tetralogy of Fallot, ASD and VSD, may be present. Symptomatic cow's- milk allergy. ${ }^{5}$ is associated with $47 \%$ of all cases of TAR syndrome and patients may present as vomiting, bloody diarrhoea and failure to thrive. Neurological abnormalities. ${ }^{6}$ are associated in about $7 \%$ of all cases of TAR syndrome.

The life expectancy is almost normal if the patient survives to two years of age. 6 In TAR syndrome, significant laboratory findings include thrombocytopenia with normal platelet morphology in peripheral smear and hypomegakaryocytic thrombocytopenia with small, basophilic, vacuolated megakaryocytes on bone marrow examination with normal or elevated plasma thrombopoietin levels. $^{7}$ Radial abnormality can be detected as early as 13 weeks by prenatal ultrasonography. The mainstay of treatment includes platelet transfusions. Prophylactic platelet transfusions to raise the platelet count above $40,000 / \mathrm{mm}^{3}$ (Extrapolated from thrombocytopenia with leukaemia) are currently pursued in patients with high risk of clinically important haemorrhage. Deformity-splinting of the limbs during infancy improves future function. The risk of bleeding, thrombocytopenia is significant particularly in the first 2 years of life, subsequently platelet count increases with age. Yet there is a reported increased risk of leukaemia with TAR syndrome. ${ }^{8}$

\section{Differential Diagnoses}

- Holt-Oram syndrome (Upper limb anomalies, ASD).

- Roberts syndrome (Hypomelia, Cleft Palate).

- Fanconi anaemia (Short Stature, Leg Bowing).

- Thalidomide Embryopathy (Phocomelia).

\section{REFERENCES}

1. Albers CA, Newbury-Ecob R, Ouwehand WH, et al. New insights into the genetic basis of TAR (thrombocytopenia-absent radii) syndrome. Curr Opin Genet Dev 2013;23(3):316-323.

2. de Ybarrondo L, Barratt MS. Thrombocytopenia absent radius syndrome. Pediatr Rev 2011;32(9):399-400.

3. Omran A, Sahmoud S, Peng J, et al. Thrombocytopenia and absent radii (TAR) syndrome associated with bilateral congenital cataract: a case report. Journal of Medical Case Reports 2012;6:168.

4. Ballmaier M, Schulze H, Strauss G, et al. Thrombopoietin in patients with congenital thrombocytopenia and absent radii: elevated serum levels, normal receptor expression, but defective reactivity to thrombopoietin. Blood 1997;90:612-619.

5. Newbury-Ecob RA, Leanage R, Raeburn JA, et al. Holt oramsyndrome: a clinical genetic study. J Med Genet 1996;33:306-7.

6. Hays RM, Bartoghesky LE, Feingold M. New features of thrombocytopenia and absent radius syndrome. Birth Defects 1982;18:115-121.

7. Go RS, Johnston KL. Acute myelogenous leukemia in an adult with thrombocytopenia with absent radii syndrome. Eur J Haematol 2003;70(4):246-248.

8. Martinovic J, Escande F, Devisme L, et al. Thrombocytopenia-absent radius (TAR) syndrome: a clinical genetic series of 14 further cases. Impact of the associated 1q21.1 deletion on the genetic counselling. Eur J Med Genet 2011;54:e471-e477. 